\title{
Prevalence of anemia among primary school children in Mymensingh: A school-based cross-sectional study \\ ${ }^{*}$ Hasan $\mathrm{MM}^{1}$, Hoque $\mathrm{MA}^{2}$, Begum $\mathrm{B}^{3}$, Akhtaruzzaman $\mathrm{M}^{4}$, Khan $\mathrm{MI}^{5}$, Chowdhury $\mathrm{B}^{6}$
}

Abstract

Anemia is a global public health problem affecting 305 million school children (SC) worldwide. It has deleterious effects in SC, including lower school achievement due to impaired cognitive development and physical growth, fatigue and poor attention span, and increased morbidity because of reduced resistance to infection. The school age is a dynamic period of growth and development. During this period physical, mental, social development of child takes place. The purpose of the study is to observe the anemia among the school aged children and to compare the urban and rural children as well as to see the correlation between malnutrition and anemia.

A school-based cross sectional study was conducted on a total of 600 School Children from 10 school, aged from 6-10 years old children of Mymensingh district. Study was conducted for a period of one year from October 2009 to September 2010. Two staged stratified random sampling method were employed to select study participants. Data on socio-demographic and socio-economic characteristics, and dietary status of children were collected using pre-tested structured questionnaire through face-to-face interview of children's caregivers. Anthropometric measurements were taken. Hemoglobin $(\mathrm{Hb})$ concentration was determined by using cyanmethaemoglobin method. Datawas analyzed by computer programmed SPSS version 14.0. P-value $<0.05$ was considered as statistically significant. Among the primary school children in Seventy one percent of our primary school children were anemic. Rural children were more sufferers in anemia.

Key words: Anemia, School children, Rural, Urban.

CBMJ 2018 January: vol. 07 no. 01 P: 24-29

\section{Introduction}

Anemia among the world's most widespread health problems especially for children (Gustavo, 2005). Iron and folic acid deficiencies that result in anemia remain a public health problem in Bangladesh (UNICEF, 2009). Iron is a component of many proteins, including enzymes and hemoglobin later being important for transport of oxygen to the deferent parts of the body (National Academy of Science, 2002). IDA that is low level of hemoglobin in combination with abnormal level of other indicators can lead to weakness, poor physical growth, increased morbidity and cognitive impairment (Gustavo, 2005).

Physical ability is reduced because in IDA the decrease in hemoglobin reduces the availability of oxygen, while in turns affects cardiac output. In IDA changes in brain iron content and distribution and in neurotransmitter function may affect the cognition (Sen, 2005). Around two billion people in the world are anemic, mostly in the lower-income countries of Africa and Asia. In Bangladesh, anemia is common among all age-groups, and both sexes are affected, especially children and women-

\footnotetext{
1. Dr. Mohammad Mahmudul Hasan, Assistant Professor (Pediatrics), Mymensingh Medical College, Mymensingh.

2. Professor Dr. Mohammad Azizul Hoque, Ex Head, Department of (Pediatrics), Mymensingh Medical College, Mymensingh.

3. Dr. Bilkis Begum, Assistant Professor (Pediatrics), Mymensingh Medical College, Mymensingh.

4. Dr. Muhammad Akhtaruzzaman, Assistant Professor (Pediatrics), Mymensingh Medical College, Mymensingh.
}

5. Dr. Mohammad Monirul Islam Khan, Assistant Professor (Pediatrics),), Shaheed Syed Nazrul Islam Medical College, Kishoreganj

6. Dr. Biswajit Chowdhury, Assistant Professor (Pediatrics), Mymensingh Medical College, Mymensingh.

Address of correspondence:

Email: hasandmc50@yahoo.com Mobile: 01711001684 
both pregnant and non-pregnant. Prevalence of deficient iron store of $30 \%$ hasbeen observed among school children aged 6-12 years (ICDDR, B. 2008).

UN Special Session, the prevalence of anemia will need to fall from $48.3 \%$ to $32.2 \%$ in preschool children, from $33.5 \%$ to $22.3 \%$ in school-aged children, from $36.3 \%$ to $24.2 \%$ in adolescents, from $33.9 \%$ to $22.6 \%$ in non-pregnant women and from $50.9 \%$ to $33.9 \%$ in pregnant women by the year 2010 (NSP, 2002). This nutritional problem of Bangladesh is due to poor nutritional sufficiency ratio, which compares actual household expenditure on food with the cost of an optimum diet. A very small proportion of households (only 4\%) could afford an adequate diet (NSP, 2006). In Bangladesh $90 \%$ school children suffers from intestinal parasites, $40 \%$ anemic, $25 \%$ are underweight, $24 \%$ are stunted (Save the Children, 2009).

The school age period is nutritionally significant because this is the prime time to built-up body stores of nutrients in preparation for rapid growth of adolescence. Therefore, it becomes very important to know the nutritional status of school going children, the building blocks of the country (Ruthika, 2008).

However, there is increasing evidence, with resulting international concern, that the high level of nutritional deprivation combined with heavy burden of disease in this age group has negative consequences for childs long term overall development. This has prompted an increase focus on the diverse needs of the school age children (school-age children, their nutrition and health).

\section{Materials and Methods}

A descriptive cross-sectional study was done among primary schools of Mymensingh district. Ten primary schools of Mymensingh district were selected. Study were conducted among 600 Primary school children (6-10 years) of from October 2009 - September 2010. School children of 6-10 years of age attending at that time were included and children beyond this age group and those who are suffering from acute illness were excluded.

Schools were selected from the Mymensingh district, Bangladesh. There are 1270 primary schools in Mymensingh district. Two stage stratified random sampling method were used. At first, we divided the primary schools into two strata as rural and urban. From that 10 primary schools (5 from each strata) were selected by random table method. Then each school is divided into 5 strata (5 classes). From each strata 12 children were selected at random. A total of 600 school going children (6-10) years were selected.

Hemoglobin estimation was done by cyanmethemoglobin method. As per age of the subject, $\pm 0.5 \mathrm{ml}$ of venous blood will be collected from pricking of index finger of the child. Fill the hemoglobin meter tube to the mark 20 with $\mathrm{N} / 10 \mathrm{HCl}$, suck the capillary or venous blood up to the mark 20, transfer the blood into acid, rinse the pipette, mix well Exactly after 5 minutes dilutes the solution by adding distilled water, match color with the standard. Reading was taken in $\mathrm{g} / \mathrm{dl}$. The WHO cut off value published by ICMR task force for the assessment of anemia.

Nutritional status of all these elected children were assessed by measuring body heights and weights $(\mathrm{kg})$, BMI were calculated. Height, weight and BMI were compared with national center for health statistics (NCHS) standard.

Detailed anthropometry, relevant nutritional history, clinical findings and laboratory records of every case were collected and recorded by interview method using a pre-designed questionnaire. Subsequently, data was analyzed by computer programmed SPSS version 14.0.

\section{Results}

This study yields following results. A total of 600 primary school children of different regions of Mymensingh district were interviewed during the study period. 
Table 1. Age and sex distribution of children.

\begin{tabular}{|l|c|c|c|c|c|c|}
\hline \multirow{2}{*}{$\begin{array}{l}\text { Age in } \\
\text { years }\end{array}$} & \multicolumn{4}{|c|}{ Sex } & \multicolumn{2}{|c|}{ Total } \\
\cline { 2 - 5 } & \multicolumn{2}{|c|}{ Boys } & \multicolumn{2}{c|}{ Girls } & \multicolumn{2}{|c|}{} \\
\cline { 2 - 6 } & $\mathbf{N}$ & $\%$ & $\mathbf{N}$ & $\%$ & $\mathbf{N}$ & $\%$ \\
\hline $6-7$ & 117 & $52.2 \%$ & 108 & $47.8 \%$ & 226 & $37.6 \%$ \\
\hline $7-8$ & 67 & $51.5 \%$ & 63 & $48.5 \%$ & 130 & $21.6 \%$ \\
\hline $8-9$ & 63 & $50.4 \%$ & 62 & $49.6 \%$ & 125 & $20.8 \%$ \\
\hline $9-10$ & 62 & $51.7 \%$ & 58 & $48.3 \%$ & 120 & $20.0 \%$ \\
\hline Total & 309 & $51.6 \%$ & 291 & $48.4 \%$ & 600 & $100.0 \%$ \\
\hline
\end{tabular}

Table 1 shows the age and sex distribution of study population. Among 600 primary school children $309(51.6 \%)$ were boys and 291 $(48.4 \%)$ were girls. Boys and girl's ratio were 1.1:1.

Fig 1. Distribution of hemoglobin level based on WHO cut off point for anemia for $6-10$ years age group.

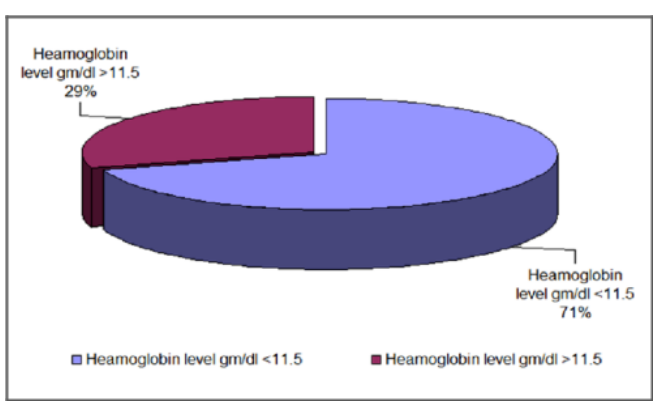

Figure 1 shows $71 \%$ of primary school children were anemic according to new WHO cut off value.

Table 2. Distribution of Hemoglobin level according to sex.

\begin{tabular}{|l|r|r|c|}
\hline \multirow{2}{*}{$\begin{array}{l}\text { Age in } \\
\text { years }\end{array}$} & \multicolumn{2}{|c|}{ Hermoglobin level } & \multirow{2}{*}{ Total } \\
\cline { 2 - 3 } & $<11.5$ & $>11.5$ & \\
\cline { 2 - 3 } & $\mathrm{N}(\%)$ & $\mathrm{N}(\%)$ & $\mathrm{N}(\%)$ \\
\hline Boys & $222(71.9)$ & $87(28.1)$ & $309(51.60)$ \\
\hline Girls & $201(69.1)$ & $90(30.9)$ & $291(48.40)$ \\
\hline Total & $423(70.5)$ & $177(29.5)$ & $600(100.0)$ \\
\hline P-value & \multicolumn{2}{|c|}{0.089} & \\
\hline $\begin{array}{l}\text { Level of } \\
\text { significance }\end{array}$ & \multicolumn{2}{|c|}{$\mathrm{NS}$} & \\
\hline
\end{tabular}

NS means not significant
Table 2 shows among 309 boys 222 (71.9\%) were anemic and 87 (28.1) were not anemic. Among 291 girls 201(69.1\%) were anemic and $90(30.9 \%)$ were not anemic. This difference between boys and girls was not statistically not significant.

Table 3. Distribution of Hemoglobin level according to sex.

\begin{tabular}{|c|c|c|c|}
\hline \multirow{3}{*}{ Area } & \multicolumn{2}{|c|}{ Hermoglobin level } & \multirow{2}{*}{ Total } \\
\hline & $<11.5$ & $>11.5$ & \\
\hline & $\mathrm{N}(\%)$ & $\mathrm{N}(\%)$ & $\mathrm{N}(\%)$ \\
\hline Rural & $232(77.4)$ & $68(22.6)$ & $68(22.6)$ \\
\hline Urban & $191(63.7)$ & 109 (36.3) & $109(36.3)$ \\
\hline Total & $423(70.5)$ & $177(29.5)$ & $177(29.5)$ \\
\hline P-value & \multicolumn{2}{|c|}{0.0001} & \\
\hline $\begin{array}{l}\text { Level of } \\
\text { significance }\end{array}$ & & \\
\hline
\end{tabular}

T- Tests

** means $(p<0.01)$

Table 3 shows Among 600 primary school children 300 were urban and 300 were rural. In rural children 232(77.4\%) were anemic and $68(22.6 \%)$ were not anemic. But in urban children 191(63.4\%) were anemic and $109(36.3 \%)$ were not anemic. This difference between urban and rural children was statistically significant.

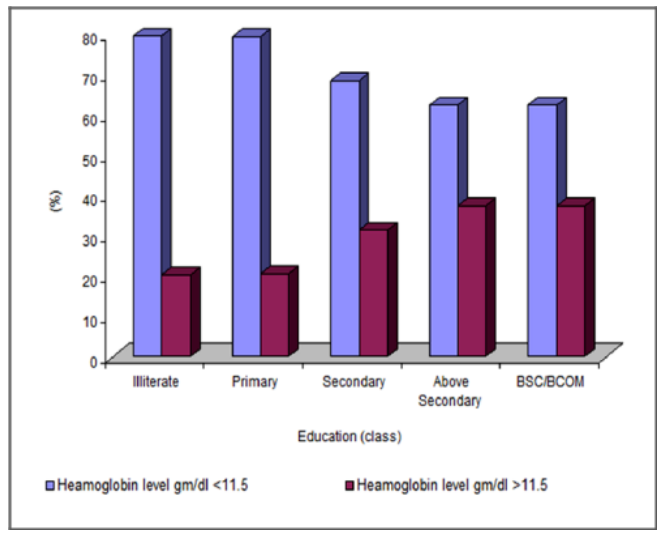

Figure 2 shows increase maternal education reduces the anemic condition of children. 
Fig 3. Graphical presentation of hemoglobin level according to income of parents.

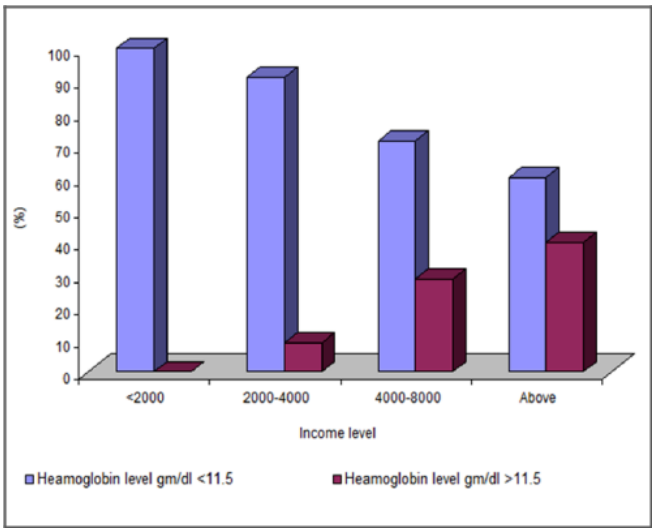

Figure 3 showing hemoglobin level according to monthly income of the parents. This shows that in low income family anemia predominant. Hemoglobin levels were more in high income family.

Table 4. Distribution of hemoglobin level according to family status of the children.

\begin{tabular}{|l|r|c|c|}
\hline \multirow{2}{*}{ Family } & \multicolumn{2}{|c|}{ Hermoglobin level } & \multirow{2}{*}{ Total } \\
\cline { 2 - 3 } & $<11.5$ & $>11.5$ & \\
\cline { 2 - 3 } & $\mathrm{N}(\%)$ & $\mathrm{N}(\%)$ & $\mathrm{N}(\%)$ \\
\hline Single & $295(69.6)$ & $129(30.4)$ & $424(70.8)$ \\
\hline Joint & $127(72.6)$ & $48(27.4)$ & $176(29.2)$ \\
\hline Total & $422(70.5)$ & $177(29.5)$ & $600(100.0)$ \\
\hline P-value & \multicolumn{2}{|c|}{0.4156} & \\
\hline $\begin{array}{l}\text { Level of } \\
\text { significance }\end{array}$ & \multicolumn{2}{|c|}{$\mathrm{NS}$} & \\
\hline
\end{tabular}

T- Tests

NS means $(p>0.05)$

Table 4 shows that among 600 children 424 are come from single family, of them $295(69.6 \%)$ were anemic and $129(30.4 \%)$ were normal and 176 children come from joint family of them $127(72.6 \%)$ were anemic and $48(27.4 \%)$ were normal. This difference was not statistically significant.
Fig 4. Relationship between hemoglobin level and weight for age of children.

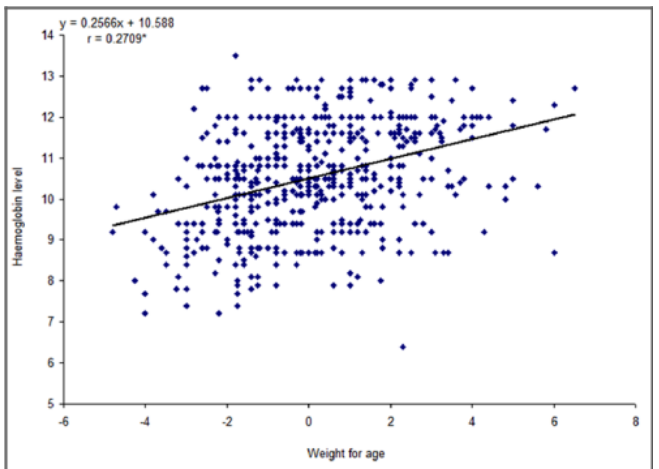

Figure 4 shows the relationship between weight for age and hemoglobin level was significant at $(P<0.05)$ level, where coefficient $(r)=.2709^{*}$

Increase of weight for age with increase of hemoglobin level.

\section{Discussion}

Nutritional status of any community is dependent upon numerous factors among them food security, food safety, social status, gender discrimination, woman's education, housing, healthcare, water and sanitation are more prevalent (Gillespie, 1997). This study tries to find out current status of nutrition and anemia in school children and relations with some risk factors for malnutrition and anemia. Present study has been done with 600 primary school children at Mymensingh to know their nutritional status, anemia and relationship between malnutrition and anemia.

It was found from the study that $51.6 \%$ of study population were boys and $48.4 \%$ were girls with Boys and girls ratio of $1.1: 1$ (Table 1). Jumrakh et al. found $53 \%$ were boys, $41 \%$ girls, Mohajira et al. (2008) showed $54.13 \%$ boys and $45.87 \%$ girls which is more or less similar to this study.

Both Jumrakh et al. and Marlina et al. showed $50 \%$ of their school children were anemic. Ruthika et al. (2008) found $65.33 \%$ and Saha et al. (1989) found $66 \%$ anemic. Among the children $71 \%$ were found anemic 
in this study (Fig-4). A study conducted in Dhaka cantonment showed that $57.7 \%$ primary school children are anemic. This study more or less similar with Ruthika et al. and Saha et al. but not with the cantonment study. In cantonment privileged group of children with better nutritional and healthcare facilities live but this study includes rural and urban population of all socioeconomic and educational background.

No marked difference in prevalence of anemia in boys and girls (Table 2). This is probably due to the fact that both boys and girls live in same environment in which they are equally exposed including the risk of parasitic infestation or other conditions.

It was found from this study that rural children are more suffered from anemia. In rural children $77.4 \%$ are anemic and $22.6 \%$ are not anemic, but in urban children $63.4 \%$ are anemic and $36.3 \%$ are not anemic (Table-3). This indicates rural children more suffered from anemia. A study done in Indonesia showed similar picture. Rural populations are economically less privileged group as well as illiteracy, ignorance, unaware of health education. Health care facility in rural area is not yet well established in our country.

Regarding income of the parents it was found in this study that prevalence of anemia is more among children's of lower income group and improved trend of hemoglobin level is observed with increase of income state. probable reason of such variation could be the better health and nutritional facilities of children among better income groups. Association between better hemoglobin with nutritional status also been shown in Hassan et al. (1988), Ahmed et al. (1984) and Vella et al. (1992).

This study also states that hemoglobin level of children significantly influenced by maternal education (Fig 2). Anemia is more prevalent in illiterate mothers. Increase maternal education reduces the anemic condition of children. This is possibly due to the reason that educated mothers are socioeconomically better group with a smaller number of children and better knowledge of nutrition and personal hygiene. This study is similar to the observation of Hasan et al. and Ahmed et al. But a study done in Dhaka cantonment area showed inverse relation.

Prevalence of anemia among the children of nuclear family is found less in comparison to joint family (table 4). In single family proper take care of the baby is possible even in limited income this is why anemia is less in single family.

Bengoa et al stated that a child who suffered from PEM could also suffered from anemia, and non-PEM child could also suffer from anemia too. This usually happens in iron deficiency anemia, because the symptom of anemia occur gradually in the long period of time. It is the same with protein deficiency which reduces total cell of precursor sensitive erythropoietin in chronic PEM (Kwiatkowski, 1999). In this study there is significant correlation was shown by Pearson's correlation co-efficient test. The relationship between weight for age and hemoglobin level was significant at $(P<0.05)$ level, where co-efficient $(r)$ $=0.2709$.

\section{Conclusion}

Anemia is a global health problem in both developing and developed countries. Anemia was more in low income group family. Illiterate mother's child is more affected then educated mother's child. Some anemic children were malnourished and some were not but there was significant relationship between anemia and malnutrition. Therefore, the legislators should make a strategy to reduce poverty and increase the awareness of women on breastfeeding, nutrition, and other associated factors to reduce anemia.

\section{References}

Bengoa JM. The problem of malnutrition. WHO chronicle 1974; 28:3-7

Child and maternal nutrition in Bangladesh, UNICEF report, 2009. 
Children Nutrition. Joint expert committee report on nutrition WHO technical report series 1971; 477: 1-80.

Gustavo J. Robins, Edward Miguel, CharuPuri Sharma (Iron deficiency anemia and school participation,2004).

ICDDR, B. Journal of Health, Population and

Research Anemia: A Public-Health Problem in Bangladesh, 2008.

Kapoor SK, Kapil U, Dwivedi SN, Anand K, Pathak $P$, Singh $P$. Comparison of HemoCue method with cyanmethemoglobin method for estimation of hemoglobin. Indian Pediatr. 2002; 39(8):743-6.

Kwiatkowski JL, West TB, Heidary N, Whitley KS, Cohen AR. Clinical and laboratory observations: severe iron deficiency anemia in young children. $J$ Pediatr 1999; 135: 514-6.

Marlina J, Iskandar Z. Noval A, Nutritional status and hemoglobin level in elementary schoolchildren PaediatrIndones 2001; 41:296-298.

Nutritional Surveillance Project Bulletin, No 17, household and community level determinants of malnutrition in Bangladesh, may, 2006.

Program for Appropriate Technology in Health (Path).Anemia Detection in Health Services Guideline for Program Managers.Seattle, U.S. Agency for International Development. 1996; pp 1137.

Public Health Nutrition: 9(5), 658-660, News and Information, 2006.
Ruthika H, Faisan A, Kavindra KK. Assessment of nutritional status of 7-10 years school going children of allahabad district, Middle east journal of scientific research, 3(3):109115, 2008.

Saha AR, Ahmed K, Iron and micronutrients supplements after Deworming :Effective way to raise the hemoglobin level of anemic children in rural Bangladesh. Bangladesh $\mathrm{J}$. of Nutrition, 1989. 2(2);1-7.

Save the children, provision of school-based health and nutrition serces, 2009. School Nutrition Program

Save the children, situation analysis of school health and nutrition in Bangladesh (June 2008).

Sen $A$ and Kanani S. Deleterious functional impact of anemia on young adolescent school girl, Indian paediatrics, 2006;43: 219226.

Vella V, Tomkins A, Borghese. Determinants of child nutrition and mortality in north west Uganda, WHO bulletin 1992;70(5):637-643. 